\title{
Risk Factors for Resistance to Proton Pump Inhibitor Maintenance Therapy for Reflux Esophagitis in Japanese Women over 60 Years
}

\author{
Akira Watanabe Ryuichi Iwakiri Daisuke Yamaguchi Toru Higuchi \\ Nanae Tsuruoka Koichi Miyahara Kayo Akutagawa Yasuhisa Sakata \\ Takehiro Fujise Yasutomo Oda Ryo Shimoda Hiroyuki Sakata \\ Kazuma Fujimoto \\ Department of Internal Medicine and Gastrointestinal Endoscopy, Saga Medical School, Saga, Japan
}

\section{Key Words}

Proton pump inhibitor $\cdot$ Helicobacter pylori $\cdot$ Reflux

esophagitis · Lumbar kyphosis $\cdot$ Hiatus hernia

\begin{abstract}
Aim: The aim of this study was to evaluate risk factors for proton pump inhibitor (PPI) resistance in older Japanese female patients with reflux esophagitis evaluated by physicians. Methods: The study included 462 Japanese female patients aged over 60 years with reflux esophagitis who received PPI maintenance therapy for more than 6 months. Results: The characteristics of all 462 patients were: age: 76.4 \pm 7.6 years, height: $147.2 \pm 6.1 \mathrm{~cm}$, weight: $49.9 \pm 8.4 \mathrm{~kg}$ and body mass index: $24.0 \pm 3.5$. The reflux esophagitis grades were A in $69.5 \%, B$ in $15.8 \%, C$ in $9.1 \%$ and $D$ in $5.6 \%$. Helicobacter pylori was positive in $60.6 \%$. Regarding PPI maintenance therapy for clinical symptoms evaluated by the attending physicians, $66.7 \%$ were 'good control', $26.8 \%$ were 'reasonable control' and 6.5\% were 'bad control: resistant'. PPI maintenance therapy was less effective in patients with more severe reflux esophagitis of grades $C$ and $D$ (OR: 0.027 ; 95\% Cl: 0.010-0.077) and negative $H$. pylori infection status (OR: 4.470; 95\% Cl: 1.631-12.247). Lumbar kyphosis and hiatus hernia were risk factors for severity grading of reflux esophagitis. Conclusions: PPI maintenance therapy evalu-
\end{abstract}

ated by attending physicians indicated that reflux esophagitis severity and negative $H$. pylori status were risk factors for treatment resistance.

Copyright ๑ 2012 S. Karger AG, Basel

\section{Introduction}

Reflux esophagitis is a common disease not only in Western countries but also in Oriental countries, including Japan [1-4]. The prevalence of reflux esophagitis, especially severe esophagitis of grades $C$ and $D$, is high in aged Japanese women [5-7]. Previous studies have suggested that risk factors for esophagitis in aged Japanese women are lumbar kyphosis, short height, hiatus hernia and negative Helicobacter pylori infection status [8, 9], whereas high body weight and lifestyle in addition to aging are important risk factors in Western countries [10-13].

Medication with a proton pump inhibitor (PPI) is the first choice of treatment for reflux esophagitis [14-19], and several studies in Japan have indicated factors for a poor response to PPI in reflux esophagitis $[8,9]$. These studies demonstrated that severe esophagitis of grades $\mathrm{C}$ and $\mathrm{D}$, negative $H$. pylori infection status and negative chronic gastritis are important factors in reflux esophagitis for a poor response to PPI. However, few studies have 
Table 1. Background characteristics of patients

\begin{tabular}{ll}
\hline & Total $(\mathrm{n}=462)$ \\
\hline Age & $76.4 \pm 7.6$ \\
$\geq 60$ to $<70$ years & $89(19.3)$ \\
$\geq 70$ to $<80$ years & $201(43.5)$ \\
$\geq 80$ years & $172(37.2)$ \\
Height, cm & $147.2 \pm 6.1$ \\
Weight, kg & $49.9 \pm 8.4$ \\
BMI & $24.0 \pm 3.5$ \\
$<25$ & $344(74.9)$ \\
$\geq 25$ & $115(25.1)$ \\
Severity of past erosive reflux esophagitis $($ Los Angeles grade) \\
Grade A & $321(69.5)$ \\
Grade B & $73(15.8)$ \\
Grade C & $42(9.1)$ \\
Grade D & $26(5.6)$ \\
H. pylori infection & \\
Negative & $182(39.5)$ \\
Positive & $280(60.6)$ \\
Hiatus hernia & \\
Negative & $164(36.2)$ \\
Positive & $289(63.8)$ \\
Lumbar kyphosis & \\
Negative & $240(52.3)$ \\
Positive & $219(47.7)$ \\
Effects of PPI & \\
Good control & $308(66.7)$ \\
Reasonable control & $124(26.8)$ \\
Bad control & $30(6.5)$ \\
\hline
\end{tabular}

Values represent number with the percentage in parentheses or mean \pm SD. BMI was not correctly measured in 3 patients. Hiatus hernia was not evaluated with endoscopic examination in 9 patients. Lumbar kyphosis was not evaluated in 3 patients.

focused on older Japanese women regarding PPI therapy for reflux esophagitis. The effects of PPI maintenance treatment on reflux esophagitis have been evaluated by several methods, including endoscopic examination [8, 9], $\mathrm{pH}$ monitoring [20] and questionnaires [21, 22], and the risk factors for a poor response to PPI maintenance therapy in reflux esophagitis did not differ significantly between these evaluation methods.

The aim of this study was to evaluate the risk factors for a poor response during PPI maintenance therapy of more than 6 months, with a focus on older Japanese women who most frequently suffer from severe reflux esophagitis. With this aim, the characteristics of reflux esophagitis in older Japanese women were analyzed, and the PPI responses were evaluated by the attending medical physicians as 'good control', 'reasonable control' and 'bad control'.

\section{Patients and Methods}

Patients

This study included 462 female Japanese patients aged over 60 years with endoscopic reflux esophagitis who received PPI maintenance therapy for more than 6 months. The maintenance therapy was conducted with $10 \mathrm{mg}$ omeprazole, $15 \mathrm{mg}$ lansoprazole or $10 \mathrm{mg}$ rabeprazole once per day. The patients were recruited from 25 hospitals, including Saga Medical School in Saga Prefecture, from March to April 2009. Those patients who had received surgical operation of the upper gastrointestinal tract were excluded from the present study. The patients were interviewed directly by their attending physicians regarding the effects of the PPI maintenance therapy on their clinical symptoms. Finally, the attending physicians evaluated the satisfaction with the PPI maintenance therapy by choosing from three answers: 'good control', 'reasonable control' or 'bad control'. A consensus meeting for evaluation criteria was held 3 times before the present study, and 'good control' and 'reasonable control' were defined as sensitive to PPI maintenance therapy, and 'bad control' was defined as resistant to PPI maintenance therapy. Lumbar kyphosis was diagnosed by the attending physicians with radiographic examination. A self-administered questionnaire was designed to collect the demographic data including age, weight, height, smoking and alcohol intake. Before the start of the PPI therapy, the patients received an endoscopic examination for diagnosis of hiatus hernia and reflux esophagitis according to the Los Angeles classification [23], and the worst severity was recorded if the patients received endoscopic examinations several times before PPI therapy. All the patients were tested for $H$. pylori infection using a urine test kit to detect anti-H. pylori immunoglobulins (Otsuka Pharmaceuticals, Tokyo, Japan). The present study was performed with approval from the Ethics Committee of the Saga Medical School.

\section{Statistical Analysis}

The patients' background characteristics were evaluated by the t test, $\chi^{2}$ test or ANOVA. Univariate and multivariate conditional logistic regression analyses with the proportional hazard model plus regression procedure were used to obtain crude and adjusted odds ratios (ORs) and 95\% confidence intervals (CIs). Factors with values of $\mathrm{p}<0.05$ in the univariate analyses were included in the multivariate analyses, and stepwise selection was employed with Statistical Analysis System (SAS) software version 9.1 (SAS Institute, Cary, N.C., USA). Differences were considered significant if the probability of the difference occurring by chance was less than 5 in $100(\mathrm{p}<0.05)$.

\section{Results}

Table 1 shows the background characteristics of the patients. The mean age was $76.4 \pm 7.6$ years. The proportions of the age ranges were as follows: $\geq 60$ to $<70$ years $19.3 \%, \geq 70$ to $<80$ years $43.5 \%$ and $\geq 80$ years $37.2 \%$. The patients had a height of $147.2 \pm 6.1 \mathrm{~cm}$, a weight of 49.9 $\pm 8.4 \mathrm{~kg}$ and body mass index (BMI) of $24.0 \pm 3.5$. The proportions of the grades of erosive reflux esophagitis 
Table 2. Comparisons of background with age

\begin{tabular}{|c|c|c|c|c|}
\hline & $\begin{array}{l}60-69 \text { years } \\
(n=89)\end{array}$ & $\begin{array}{l}70-79 \text { years } \\
(\mathrm{n}=201)\end{array}$ & $\begin{array}{l}>80 \text { years } \\
(\mathrm{n}=172)\end{array}$ & $\mathrm{p}$ value \\
\hline Mean height $\pm \mathrm{SD}, \mathrm{cm}$ & $150.9 \pm 4.5$ & $148.1 \pm 5.2$ & $144.2 \pm 6.4$ & $<0.01$ \\
\hline Mean weight $\pm \mathrm{SD}, \mathrm{kg}$ & $54.8 \pm 9.4$ & $50.4 \pm 7.4$ & $46.7 \pm 7.6$ & $<0.01$ \\
\hline Mean BMI \pm SD & $24.1 \pm 3.5$ & $23.0 \pm 3.3$ & $22.4 \pm 3.1$ & $<0.01$ \\
\hline Los Angeles classification $(\mathrm{A}+\mathrm{B}$ vs. $\mathrm{C}+\mathrm{D})$ & $84 / 5$ & $173 / 28$ & $137 / 35$ & $<0.01$ \\
\hline \multicolumn{5}{|l|}{ H. pylori infection } \\
\hline Positive, $\%$ & 67 & 59.2 & 58.5 & NS \\
\hline \multicolumn{5}{|l|}{ Hiatus hernia } \\
\hline Positive, $\%$ & 44.3 & 61.7 & 74.3 & $<0.01$ \\
\hline \multicolumn{5}{|l|}{ Lumbar kyphosis } \\
\hline Positive, \% & 12.5 & 38.5 & 76.4 & $<0.01$ \\
\hline PPI effects (resistant/effective) & $2 / 87$ & $15 / 186$ & $13 / 159$ & NS \\
\hline
\end{tabular}

NS = Not significant; resistant $=$ bad control; effective $=$ reasonable + good control .

Table 3. Univariate analyses of risk factors for resistance to PPI maintenance therapy

\begin{tabular}{|c|c|c|c|c|}
\hline & Effective $(\mathrm{n}=432)$ & Resistant $(\mathrm{n}=30)$ & OR & $95 \% \mathrm{CI}$ \\
\hline Mean age $\pm S D$, years & $76.3 \pm 7.7$ & $77.9 \pm 6.1$ & 0.971 & $0.924-1.021$ \\
\hline Mean height $\pm \mathrm{SD}, \mathrm{cm}$ & $147.2 \pm 6.1$ & $146.8 \pm 6.7$ & 1.010 & $0.951-1.073$ \\
\hline Mean weight $\pm S D, \mathrm{~kg}$ & $49.8 \pm 8.4$ & $50.5 \pm 8.0$ & 0.990 & $0.948-1.034$ \\
\hline Mean BMI $\pm S D$ & $23.0 \pm 3.5$ & $23.4 \pm 3.0$ & 0.967 & $0.873-1.071$ \\
\hline Los Angeles classification (A + B vs. C + D) & $388 / 43$ & $6 / 25$ & 0.022 & $0.008-0.061^{*}$ \\
\hline \multicolumn{5}{|l|}{ H. pylori infection } \\
\hline Positive, \% & 63.3 & 20.0 & 6.991 & $2.766-17.272^{*}$ \\
\hline \multicolumn{5}{|l|}{ Hiatus hernia } \\
\hline Positive, $\%$ & 62.9 & 66.7 & 0.846 & $0.386-1.853$ \\
\hline \multicolumn{5}{|l|}{ Lumbar kyphosis } \\
\hline Positive, \% & 46.5 & 65.5 & 0.458 & $0.208-1.007$ \\
\hline
\end{tabular}

${ }^{*} \mathrm{p}<0.01$.

were grade $A$ in $69.5 \%(n=321)$, grade $B$ in $15.8 \%(n=73)$, grade $C$ in $9.1 \%(n=42)$ and grade $D$ in $5.6 \%(n=26)$. The ratio of $H$. pylori infection was $60.6 \%$, endoscopic hiatus hernia was complicated in $63.8 \%$ and the ratio of lumbar kyphosis was $47.7 \%$. Regarding PPI maintenance therapy for clinical symptoms, $66.7 \%$ of all patients were categorized as 'good control', $26.8 \%$ as 'reasonable control' and $6.5 \%$ as 'bad control'.

Table 2 shows the patients' characteristics divided into three age groups of 60-69 years, 70-79 years and $>80$ years. The height, weight and BMI decreased in an age-related manner. The ratios of severe reflux esophagitis of grades $\mathrm{C}$ and $\mathrm{D}$, hiatus hernia and kyphosis significantly increased with age. Aging did not influence the therapeutic evaluation of PPI or the H. pylori infection ratio.

The categorizations of the PPI effects (resistant vs. sensitive) evaluated by the attending physicians are shown in table 3. PPI maintenance therapy was more effective in patients with mild reflux esophagitis of grades $A$ and $B$, and was also more effective in $H$. pylori-positive than in H. pylori-negative patents. Other factors including age, height, weight, BMI, hiatus hernia and lumbar kyphosis had no influence on PPI maintenance therapy. The patients were prescribed three different PPI in the present study for maintenance therapy of reflux esophagitis, 10 mg omeprazole, $15 \mathrm{mg}$ lansoprazole or $10 \mathrm{mg}$ rabeprazole (data are not shown in table 3 ). The effect was not differ- 
Table 4. Multivariate logistic regression analyses of risk factors for resistance to PPI maintenance therapy

\begin{tabular}{lccc}
\hline Variable & OR & $95 \%$ CI & p value \\
\hline $\begin{array}{l}\text { Los Angeles classification (A + B vs. C + D) } \\
\text { LA: C + D }\end{array}$ & 0.027 & $0.010-0.077$ & $<0.01$ \\
$\begin{array}{l}\text { H. pylori infection } \\
\text { Positive }\end{array}$ & 4.470 & $1.631-12.247$ & $<0.01$ \\
\hline LA = Los Angeles. & & \\
\hline
\end{tabular}

Table 5. Comparison between two Los Angeles (LA) classification groups: $\mathrm{A}+\mathrm{B}$ vs. $\mathrm{C}+\mathrm{D}$

\begin{tabular}{|c|c|c|c|}
\hline & $\begin{array}{l}\text { LA: A + B } \\
(n=394)\end{array}$ & $\begin{array}{l}\mathrm{LA}: \mathrm{C}+\mathrm{D} \\
(\mathrm{n}=68)\end{array}$ & $\mathrm{p}$ value \\
\hline Mean age $\pm S D)$, years & $75.9 \pm 7.7$ & $79.2 \pm 6.3$ & $<0.01$ \\
\hline Mean height $\pm \mathrm{SD}, \mathrm{cm}$ & $147.5 \pm 5.9$ & $145.1 \pm 6.8$ & $<0.01$ \\
\hline Mean weight $\pm S D, k g$ & $50.1 \pm 8.5$ & $48.8 \pm 8.0$ & NS \\
\hline $\begin{array}{l}\text { Mean BMI } \pm \text { SD } \\
\text { H. pylori infection }\end{array}$ & $23.0 \pm 3.6$ & $23.2 \pm 3.2$ & NS \\
\hline Positive, \% & 63.6 & 38.2 & $<0.01$ \\
\hline Hiatus hernia & & & \\
\hline $\begin{array}{c}\text { Positive, } \% \\
\text { Lumbar kyphosis }\end{array}$ & 61.3 & 79.7 & $<0.01$ \\
\hline Positive, $\%$ & 43.5 & 74.2 & $<0.01$ \\
\hline
\end{tabular}

NS $=$ Not significant

Table 6. Comparison between two lumbar kyphosis groups: positive vs. negative

\begin{tabular}{|c|c|c|c|}
\hline & $\begin{array}{l}\text { Positive } \\
(\mathrm{n}=219)\end{array}$ & $\begin{array}{l}\text { Negative } \\
(\mathrm{n}=240)\end{array}$ & $\begin{array}{l}\mathrm{p} \\
\text { value }\end{array}$ \\
\hline Mean age $\pm S D$, years & $80.6 \pm 6.3$ & $72.6 \pm 6.7$ & $<0.01$ \\
\hline Mean height $\pm S D, c m$ & $144.3 \pm 5.9$ & $149.7 \pm 5.1$ & $<0.01$ \\
\hline Mean weight $\pm \mathrm{SD}, \mathrm{kg}$ & $48.0 \pm 8.0$ & $51.6 \pm 8.4$ & $<0.01$ \\
\hline Mean BMI $\pm S D$ & $23.0 \pm 3.4$ & $23.0 \pm 3.6$ & NS \\
\hline $\begin{array}{c}\text { Los Angeles classification } \\
\quad(\mathrm{A}+\mathrm{B} \text { vs. } \mathrm{C}+\mathrm{D})\end{array}$ & $169 / 50$ & $222 / 18$ & $<0.01$ \\
\hline H. pylori infection & & & \\
\hline Positive, $\%$ & 57.3 & 63.8 & NS \\
\hline Hiatus hernia & & & \\
\hline Positive, \% & 78.2 & 49.4 & $<0.01$ \\
\hline
\end{tabular}

Lumbar kyphosis was not evaluated in 3 patients. NS $=$ Not significant. ent among these three PPI: omeprazole versus lansoprazole versus rabeprazole, sensitive 116, 153 and 163 patients, and resistant 8,15 and 7 patients, respectively.

The results of the multivariate analyses are shown in table 4 . The risk factors for resistant to PPI maintenance therapy were severe reflux esophagitis of grades $\mathrm{C}$ and $\mathrm{D}$ (OR: 0.027; 95\% CI: 0.010-0.077) and negative $H$. pylori infection status (OR: 4.470; 95\% CI: 1.631-12.247).

Comparisons of the patients' characteristics for several factors including the severity of reflux esophagitis and lumbar kyphosis were carried out. Severe reflux esophagitis was more common in patients with older age, short height, negative $H$. pylori infection, hiatus hernia and lumbar kyphosis (table 5). Complications of lumbar kyphosis were related to older age, short height, low body weight, severe reflux esophagitis and hiatus hernia (table 6).

\section{Discussion}

This study targeted elderly women, and the therapeutic effects of PPI maintenance therapy on reflux esophagitis were evaluated by their attending physicians. The results revealed that more severe reflux esophagitis (grades $\mathrm{C}$ and $\mathrm{D}$ ) and negative $H$. pylori infection status were risk factors for treatment resistance in elderly Japanese women with reflux esophagitis. Specifically, PPI maintenance therapy was less effective in patients with severe reflux esophagitis of grades C and D (OR: 0.027; 95\% CI: 0.010-0.077) and negative $H$. pylori infection status (OR: 4.470; 95\% CI: 1.631-12.247), while body weight, $\mathrm{BMI}$ and age were not related to PPI maintenance therapy. These risk factors for older Japanese women were similar to the risk factors demonstrated in previous studies focusing on Japanese patients with reflux esophagitis [8, $9,20]$. Most previous studies evaluated the effects of PPI on reflux esophagitis by endoscopic examination, $\mathrm{pH}$ monitoring and questionnaires [8, 9, 20-22, 24-33]. However, the present study indicates that evaluation of the therapeutic effects of PPI by the physicians who take care of reflux patients in daily clinical situations may be convenient and useful compared with evaluation by endoscopy and/or questionnaires.

This study confirmed that negative $H$. pylori infection status was a risk factor for resistance to PPI treatment in patients with reflux esophagitis $[8,9]$. The ratio of $H$. $p y$ lori infection was still high, up to $60 \%$, in the present study, and the positive rate increases in an age-related manner in Japan $[34,35]$, indicating that the percentage 
of PPI resistance in patients with reflux esophagitis may increase in the near future in Japan. The increased prevalence of reflux esophagitis in aged females was supported by previous reports that the ratio of negative $H$. pylori infection status was high in patients with reflux esophagitis compared with control subjects in Japan [36-42].

The percentage of patients with severe esophagitis of grades $\mathrm{C}$ and $\mathrm{D}$ was $14.7 \%$, which was higher than the percentages in other studies performed in Japan, but did not differ significantly from those in previous Japanese studies focusing on elderly females [3-7, 43-46], although the prevalence of severe esophagitis in females was the same as that in males in Western countries [47]. The present study further indicated that the risk factors for an increase in severe reflux esophagitis of grades C and D in aged females were lumbar kyphosis, hiatus hernia, negative $H$. pylori infection status, short height and high age, which were compatible with previous reports $[3-5,8,9]$.
Although both lumbar kyphosis (positive rate: $47.7 \%$ ) and hiatus hernia (positive rate: $63.8 \%$ ) were closely related to the severity of reflux esophagitis, as shown in previous studies [5, 48-50], those studies did not indicate that these two factors were risk factors for PPI resistance. The reason for this discrepancy was not apparent in this study, although negative for $H$. pylori infection might be a more potent risk factor for PPI resistance in older Japanese female patients with reflux esophagitis.

In conclusion, our study demonstrated the risk factors for PPI resistance in older Japanese females with reflux esophagitis based on evaluation by the attending physicians. More severe reflux esophagitis (grades $\mathrm{C}$ and $\mathrm{D}$ ) and negative $H$. pylori infection status were risk factors for treatment resistance in elderly Japanese women with reflux esophagitis. These findings provide an important clinical tool for medical physicians to treat PPI-refractory erosive esophagitis.

\section{References}

1 Vakil N: Disease definition, clinical manifestations, epidemiology and natural history of GERD. Best Prac Res Clin Gastroenetrol 2010;24:759-765.

-2 Fock KM, Poh CH: Gastroesophageal reflux disease. J Gastroenetrol 2010;45:808-815.

$\checkmark 3$ Fujiwara Y, Arakawa T: Epidemiology and clinical characteristics of GERD in the Japanese populations. J Gastroenterol 2009;44: 518-534.

$\checkmark 4$ Kinoshita Y, Adachi K, Hongo M, Haruma $\mathrm{K}$ : Systematic review of the epidemiology of gastroesophageal reflux disease in Japan. J Gastroenterol 2011;94:1092-1103.

5 Furukawa N, Iwakiri R, Koyama T, Okamoto K, Yoshida T, Kashiwagi Y, Ohyama T, Noda T, Sakata H, Fujimoto K: Proportion of reflux esophagitis in 6010 Japanese adults: prospective evaluation by endoscopy. J Gastroenterol 1999;34:441-444.

-6 Shimazu T, Matsui T, Furukawa K, Oshige K, Mitsuyasu T, Kiyomizu A, Ueki T, Yao T: A prospective study of the prevalence of gastroesophageal reflux disease and confounding factors. J Gastroenterol 2005;40:866872.

$\checkmark 7$ Mishima I, Adachi K, Arima N, Amano K, Takashima T, Moritani M, Furuta K, Kinoshita Y: Prevalence of endoscopically negative and positive gastroesophageal reflux disease in the Japanese. Scand J Gastroenterol 2005;40:1005-1009.

8 Fujimoto K, Hongo M: Risk factors for relapse of erosive GERD during long-term maintenance treatment with proton pump inhibitor: a prospective multicenter study in Japan. J Gastroenterol 2010;45:1193-1200.
-9 Furuta T, Shimatani T, Sugimoto M, Ishihara S, Fujiwara Y, Kusano M, Koike T, Hongo M, Chiba T, Kinoshita Y, Acid-Related Symptom Research Group: Investigation of pretreatment prediction of proton pump inhibitor (PPI)-resistant patients with gastroesophageal reflux disease and the dose escalation challenge of PPIs-TORNADO study: a multicenter prospective study by the Acid-Related Symptom Research Group in Japan. J Gastroenterol 2011;46:1273-1283.

10 Fass R, Shapiro M, Dekel R, Sewell J: Systematic review: proton-pump inhibitor failure in gastro-oesophageal reflux disease - where next? Aliment Pharmacol Ther 2005;22:7994.

11 Hampel H, Abrahan NS, El-Serag HB: Metaanalysis: obesity and the risk for gastroesophageal reflux disease and its complications. Ann Intern Med 2005;143:199-211.

12 El-Serag H: The association between obesity and GERD: a review of the epidemiological evidence. Dig Dis Sci 2008;53:2307-2312.

-13 Dickman R, Boaz M, Aizic S, Beniashvili Z, Fass R, Niv Y: Comparison of clinical characteristics of patients with gastroesophageal reflux disease who failed proton pump inhibitor therapy versus those who fully responded. J Neurogastroenterol Motil 2011; 17:387-394.

14 Dekel R, Morse C, Fass R: The role of proton pump inhibitors in gastrooesophageal reflux disease. Drugs 2004;64:277-295.

15 Coron E, Hatlebakk JG, Glamiche JP: Medical therapy of gastroesophageal reflux disease. Curr Opin Gastroenterol 2007;23:434439.
16 Chiba N, De Gara CJ, Wilkinson JM, Hunt $\mathrm{RH}$ : Speed of healing and symptom relief in grade II to IV gastroesophageal reflux disease: a meta-analysis. Gastroenterology 1997;112:1798-1810.

17 Oda K, Iwakiri R, Hara M, Watanabe K, Danjo A, Shimoda R, Kikkawa A, Ootani A, Sakata H, Tsunada S, Fujimoto K: Dysphagia associated with gastroesophageal reflux disease is improved by proton pump inhibitor. Dig Dis Sci 2005;50:1921-1926.

18 Habu Y, Maeda K, Kusuda T, Yoshino T, Shio S, Yamazaki M, Hayakumo T, Hayashi K, Watanabe Y, Kawai K: 'Proton-pump inhibitor-first' strategy versus 'step-up' strategy for the acute treatment of reflux esophagitis: a cost-effectiveness analysis in Japan. J Gastroenterol 2005;40:1029-1035.

19 Caro JJ, Salas M, Ward A: Healing and relapse rates in gastroesophageal reflux disease treated with the newer proton-pump inhibitors lansoprazole, rabeprazole, and pantoprazole compared with omeprazole, ranitidine, and placebo: evidence from randomized clinical trials. Clin Ther 2001;23: 998-1017.

20 Shimatani T, Sugimoto M, Nishino M, Adachi K, Furuta K, Ito M, Kurosawa S, Manabe N, Mannen K, Hongo M, Chiba T, Kinoshita Y, Acid-Related Symptom Research Group: predicting the efficacy of proton pump inhibitors in patients with non-erosive reflux disease before therapy using dual-channel 24-h esophageal $\mathrm{pH}$ monitoring. J Gastroenterol Hepatol 2012;27:899-906. 
21 Danjo A, Yamaguchi K, Fujimoto K, Saitoh $\mathrm{T}$, Inamori $\mathrm{M}$, Ando $\mathrm{T}$, Shimanani $\mathrm{T}$, Adachi K, Kinjo F, Kuribayashi S, Mitsufuji S, Fujiwara Y, Koyama S, Akiyama J, Takagi A, Manabe N, Miwa H, Shimoyama Y, Kusano M: Comparison of endoscopic findings with symptom assessment systems (FSSG and QUEST) for gastroesophageal reflux disease in Japanese centres. J Gastroenterol Hepatol 2009;24:633-638.

-22 Kusano M, Shimoyama Y, Sugimoto S, Kawamura O, Maeda M, Minashi K, Kuribayashi S, Higuchi T, Zai H, Ino K, Horikoshi T, Sugiyama T, Koki M, Ohwada T, Mori M: Development and evaluation of FSSG: frequency scale for the symptoms of GERD. J Gastroenterol 2004;39:888-891.

-23 Armstrong D, Bennett JR, Blum AL, Dent J, De Dombal FT, Galmiche JP, Lundell L, Margulies M, Richter JE, Spechler SJ, Tytgat GN, Wallin L: The endoscopic assessment of esophagitis: a progress report on observer agreement. Gastroenterology 1996;111:8592.

24 Arihiro S, Kato T, Ito K, Saruta M, Nikami T, Suzuki T, Tajiri H: Correlation between symptomatic improvement and quality of life in patients with reflux and dyspeptic symptoms. J Clin Biochem Nutr 2011;50: 205-210.

25 Hongo M, Miwa H, Kusano M, J-FAST Group: Effect of rabeprazole treatment on health-related quality of life and symptoms in patients with reflux esophagitis: a prospective multicenter observational study in Japan. J Gastroenterol 2011;46:297-304.

26 Loffeld SM, Dackus GM, Loffeld RJ: The long-term follow-up of patients with endoscopically diagnosed reflux oesophagitis with specific emphasis to complaints. Eur J Gastroenterol Hepatol 2011;23:1122-1126.

-27 Shimizu Y, Dobashi K, Kusano M, Mori M: Different gastoroesophageal reflux symptoms of middle-aged to elderly asthma and chronic obstructive pulmonary disease (COPD) patients. J Clin Biochem Nutr 2012; 50:169-175.

-28 Shimazu H, Nakaji G, Fukata M, Odashiro K, Maruyama T, Akashi K, Fukuoka F-Scale Trial Group: Relationship between atrial fibrillation and gastroesophageal reflux disease: a multicenter questionnaire survey. Cardiology 2011;119:217-223.

29 Yoshida S, Nii M, Date M: Effects of omeprazole on symptoms and quality of life in Japanese patients with reflux esophagitis: final results of OMAREE, a large-scale clinical experience investigation. BMC Gastroenterol 2011;11:15.
30 Kakuta E, Yamashita N, Katsube T, Kushiyama $Y$, Suetsugu H, Furuta K, Kinoshita $Y$ : Abdominal symptom-related QOL in individuals visiting an outpatient clinic and those attending an annual health check. Intern Med 2011;50:1517-1522.

-31 Takada K, Matsumoto S, Kojima E, Iwata S, Okachi S, Ninomiya K, Morioka $\mathrm{H}$, Tanaka K, Enomoto Y: Prospective evaluation of the relationship between acute exacerbations of COPD and gastroesophageal reflux disease diagnosed by questionnaire. Respir Med 2011;105:1531-1536.

32 Hirata A, Kishida K, Nakatsuji H, Inoue K, Hiuge-Shimizu A, Funahashi T, Shimomura I: High prevalence of gastroesophageal reflux symptoms in type 2 diabetics with hypoadiponectinemia and metabolic syndrome. Nutr Metab 2012;9:4.

33 Oridate N, Tokashiki R, Watanabe Y, Taguchi A, Kawamura O, Fujimoto K: Endoscopic laryngeal findings in Japanese patients with laryngopharyngeal reflux symptoms. Int J Otolaryngol 2012;2012:908154.

34 Suzuki H, Hibi T, Marshall BJ: Helicobacter pylori: present status and future prospects in Japan. J Gastroenterol 2007;42:1-15.

35 Asaka M, Kimura T, Kudo M, Takeda H, Mitani S, Miyazaki T, Miki K, Graham FY: Relationship of Helicobacter pylori to serum pepsinogens in an asymptomatic Japanese population. Gastroenterology 1992; 102: $760-766$.

36 Haruma K, Hamada H, Mihara M, Kamada T, Yoshihara M, Sumii K, Kajiyama G, Kawanishi M: Negative association between Helicobacter pylori infection and reflux esophagitis in older patients: case-control study in Japan. Helicobacter 2000;5:24-29.

- 37 Manabe N, Haruma K, Kamada T, Kusunoki $\mathrm{H}$, Inoue $\mathrm{K}$, Murao $\mathrm{T}$, Imamura $\mathrm{H}$, Matsumoto $\mathrm{H}$, Tarumi K, Shiotani A, Hara J: Changes of upper gastrointestinal symptoms and endoscopic findings in Japan over 25 years. Intern Med 2011;50:1357-1363.

38 Kawai T, Yamamoto K, Fukuzawa M, Yamagishi T, Yagi K, Fukuzawa M, Katanoka M, Kawakami K, Ito T, Sakai Y, Moriyasu F, Takagi Y, Aoki T: Helicobacter pylori infection and reflux esophagitis in young and middle-aged Japanese subjects. J Gastroenterol Hepatol 2010;25(suppl 1):S80-S85.

-39 Fujimoto K, Hongo M, Maintenance Study Group: Risk factors for relapse of erosive GERD during long-term maintenance treatment with proton pump inhibitor: a prospective multicenter study in Japan. J Gastroenterol 2010;45:1193-1200.
40 Fujisawa T, Kumagai T, Akamatsu T, Kiyosawa K, Matsunaga Y: Changes in seroepidemiological pattern of Helicobacter pylori and hepatitis A virus over the last 20 years in Japan. Am J Gastroenterol 1999;94:2094-2099.

- 41 Kawamura A, Adachi K, Takashima T, Murao $M$, Katsube T, Yuki $M$, Watanabe $M$, Kinoshita Y: Prevalence of functional dyspepsia and its relationship with Helicobacter pylori infection in a Japanese population. J Gastroenterol Hepatol 2001;16:384-388.

42 Koike T, Ohara S, Sekine H, Iijima K, Kato K, Shimosegawa T, Toyota T: Helicobacter pylori infection inhibits reflux esophagitis by inducing atrophic gastritis. Am J Gastroenterol 1999;94:3468-3472.

43 Yamagishi H, Koike T, Ohara S, Kobayashi S, Ariizumi K, Abe Y, Iijima K, Imatani A, Inomata Y, Kato K, Shibuya D, Aida S, Shimosegawa T: Prevalence of gastroesophageal reflux symptoms in a large unselected general population in Japan. World J Gastroenterol 2008; 14:1358-1364.

- 44 Furuta K, Kushiyama Y, Kawashima K, Shibagaki K, Komazawa Y, Fujishiro H, Kitajima N, Adachi K, Kinoshita Y: Comparisons of symptoms reported by elderly and nonelderly patients with GERD. J Gastroenterol 2012;47:144-149.

45 Watanabe T, Urita Y, Sugimoto M, Miki K: Gastroesophageal reflux disease symptoms are more common in general practice in Japan. World J Gastroenterol 2007;13:42194223

46 Tominaga K, Iwakiri R, Fujimoto K, Fujiwara Y, Tanaka M, Shimoyama Y, Umegaki E, Higuchi K, Kusano M, Arakawa T: Rikkunshito improves symptoms in PPI-refractory GERD patients: a prospective, randomized, multicenter trial in Japan. J Gastroenterol 2012;47:284-292.

47 Nusrat S, Nusrat S, Bielefeldt K: Reflux and sex: what drives testing, what drives treatment? Eur J Gastroenterol Hepatol 2012;24: 233-247.

48 Kusano M, Hashizume K, Ehara Y, Shimoyama Y, Kawamura O, Mori M: Size of hiatus hernia correlates with severity of kyphosis, not with obesity, in elderly Japanese women. J Clin Gastroenterol 2008;42:345-350.

-49 Amano K, Adachi K, Katsube T, Watanabe M, Kinoshita Y: Role of hiatus hernia and gastric mucosal atrophy in the development of reflux esophagitis in the elderly. J Gastroenterol Hepatol 2001;16:132-136.

50 Iwakiri R, Fujimoto K: Importance of vertebral fracture and body mass index on the pathogenesis of gastroesophageal reflux disease. Intern Med 2008;47:1551-1553. 